\title{
Heat Transfer Characteristics of Work Fluid Including Phase Change Material That Flow into Heating Surface from Narrow Path
}

\author{
Shin-Ichi Morita1, Yasutaka Hayamizu1, Takanobu Yamada², Akihiko Horibe ${ }^{3}$, \\ Naoto Haruki ${ }^{3}$, Toshiaki Setoguchi' ${ }^{4}$ Kazuma Adachi ${ }^{5}$ \\ ${ }^{1}$ Department of Mechanical Engineering, National Institute of Technology, Yonago College, Yonago, Japan \\ ${ }^{2}$ Department of Mechanical Engineering, Kitami Institute of Technology, Kitami, Japan \\ ${ }^{3}$ Graduate School of Natural Science and Technology, Okayama University, Okayama, Japan \\ ${ }^{4}$ Department of Advanced Technology Fusion, Saga University, Saga, Japan \\ ${ }^{5}$ Graduate School of Machine Creative Engineering, Nagaoka University of Technology, Nagaoka, Japan \\ Email: s-morita@yonago-k.ac.jp
}

Received 29 October 2014; revised 21 November 2014; accepted 19 December 2014

Copyright (C) 2014 by authors and Scientific Research Publishing Inc.

This work is licensed under the Creative Commons Attribution International License (CC BY). http://creativecommons.org/licenses/by/4.0/

\section{Open Access}

\section{Abstract}

Use of the low temperature (less than $100^{\circ} \mathrm{C}$ ) energy contributes to effective use of heat resources. The cost recovery by power generation is difficult by using an existing system (the binary cycle or the thermoelectric conversion element), because the initial investment is large. The final purpose of this research is development of the low temperature difference drive engine supposing use in a hot-springs resort as a power source for electric power generation. In order that a traveler may look at and delight a motion of an engine, it is made to drive at low-speed number of rotations. An engine cycle of this study is aimed at the development of Stirling cycle engine which can maintain high efficiency in small size. This kind of engine has simple structure; it brings low cost, and it is easy to perform maintenance. However, it is difficult to obtain enough output by this type of engine, because of its low temperature difference. This paper deals with the heat transfer characteristic that the working fluid including a phase change material flows into the heating surface from the narrow path. In order to increase the amount of the heat transmission, Diethylether is added to the working fluid. Diethylether is selected as a phase change material (PCM) that has the boiling point which exists between the heat source of high temperature and low temperature. The parameters of the experiment are additive amount of PCM, rotational speed of the displacer piston and temperature of heat transfer surface. It is shown that it is possible to make exchange of heat amount increase by adding phase change material. The result of this research shows the optimal condition of the difference in temperature in heat processing, number of revolutions, and addition concentration of PCM. 


\section{Keywords}

\section{Phase Change Material, Heat Transfer, Low Temperature Difference, Working Fluid}

\section{Introduction}

Many attentions have been paid to the researches which use the low-temperature heat source for the purpose of effective use of energy. Using of the low temperature (less than $100^{\circ} \mathrm{C}$ ) energy contributes to effective use of heat resources. Japan has more than 3000 [1] places of hot-springs resorts with accommodations. That number is the highest in the world. The number of hot-spring resource in Japan is about 27,000 that are including the resource which has 12,000 places of more than $42^{\circ} \mathrm{C}$ hot-spring temperature and about 900 places of the water vapor gas. Although the electric power generation by using the binary cycle [2] or the thermoelectric conversion element [3] is beginning to be tried at some places, since initial investment is large, a very long period is needed for cost recovery by power generation.

The final purpose of this research is development of the low temperature difference drive engine supposing use in a hot-springs resort as a motor for electric power generation. In order that a traveler may look at and delight a motion of an engine, it is made to drive at low-speed number of rotations. An engine cycle of this study is aimed at the Stirling cycle which can maintain high efficiency also in small size. This kind of engine has simple structure, it brings low cost, and it is easy to perform maintenance. However, it is difficult to obtain enough output by this type of engine, because of its low temperature difference. Authors found out the increasing of engine output by adding a little phase change material which has the boiling point between the source of high temperature and the source of low temperature in a working fluid. This paper deals with the heat transfer characteristic that the work fluid including phase change material flows into the heating surface from the narrow path. Some researches [4]-[6] on heat transfer evaluation of a working fluid have been published, but these studies were examined by using a single phase gas as working fluid. In order to increase the amount of the heat transmission, a little amount of Diethylether $\left(\mathrm{C}_{4} \mathrm{H}_{10} \mathrm{O}\right.$, molecular weight $74.12 \mathrm{~g} / \mathrm{mol}$, density $0.7134 \mathrm{~g} / \mathrm{cm}^{3}$ on liquid phase, boiling point $34.6^{\circ} \mathrm{C}$, colorless liquid), as a phase change material, is added to the working fluid. Diethylether is selected as a phase change material (PCM) that has the boiling point between the source of high temperature and low temperature.

\section{Experimental Procedure}

\subsection{Experimental Apparatus}

Figure 1 shows the schematic diagram of the experimental apparatus of this study. The experimental apparatus consists of a test section, an actuator, two sets of constant temperature bath and data logger. The examination part is made of the clear acrylic resin, and thermal insulation panels $10 \mathrm{~mm}$ in thickness have been stuck on the internal surface. The inner size of the test section is $120 \mathrm{~mm}$ in height, $300 \mathrm{~mm}$ in width and $150 \mathrm{~mm}$ in length. The upper surface and the bottom surface of the test section are made of copper plate $3 \mathrm{~mm}$ in thickness, and are a cooling area and a heating side, respectively. The cooling and heating surface temperature are measured by 6 points of $\mathrm{K}$ type thermo couples that have $0.18 \mathrm{~mm}$ diameter. The heating and cooling surface temperature are controlled within $\pm 0.2 \mathrm{~K}$ of the experimental condition. The pressure change on the experiment is measured by the pressure sensor (Keyence AP-43, range $0-+1.000 \mathrm{MPa}$, resolution $0.1 \mathrm{kPa}$, response time $1 \mathrm{~ms}$ ) that is attaching to the acrylic test sections wall. Putting the phase change material into the test section is performed using digital buret (Continuous E $2.5 \mathrm{ml} / \mathrm{rev}$., minimum scale $0.01 \mathrm{ml}$, accuracy $\pm 0.2 \%$ ). A displacer piston that is set in the test section is connected to an actuator (Misumi single axis robot RSD2 position accuracy $\pm 0.02 \mathrm{~mm}$, maximum load $25 \mathrm{~kg}$, stroke $50-300 \mathrm{~mm}$ ) through a SUS seal rod ( $3 \mathrm{~mm}$ in diameter), and is moved up and down by computer control. The increasing of pressure in the test section is caused by moving of displacer piston to upper side. The process distance of a displacer piston is $60 \mathrm{~mm}$. Working fluid flows through $3 \mathrm{~mm}$ gaps (length of $150 \mathrm{~mm}$ ) of side wall by up-and-down motion of a displacer piston. The working fluid is flowed from upper side to bottom side by moving of displacer piston, so that the pressure of the test section is increased by heat exchange between working fluid and hot heat transfer surface. 


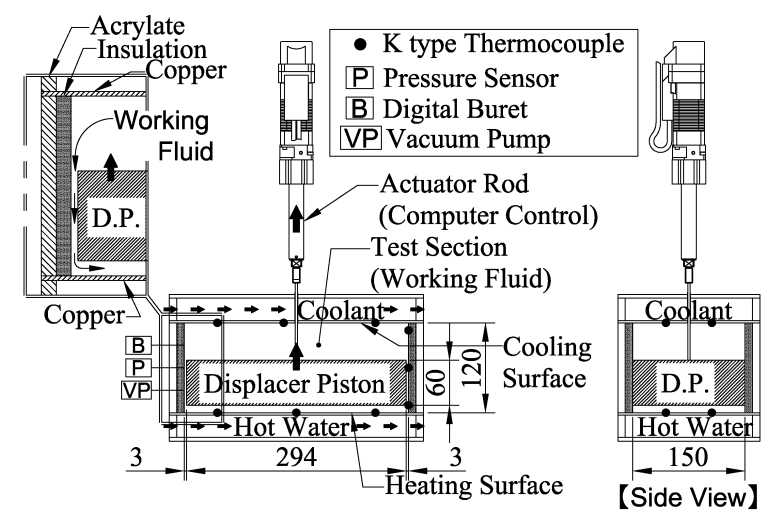

Figure 1. Experimental apparatus and measuring system.

\subsection{Thermophysical Properties of Test Samples}

The working fluid of this study research is air or air-Diethylether mixture gas. Diethylether $\left(\mathrm{C}_{4} \mathrm{H}_{10} \mathrm{O}\right)$ is selected as the phase change material which has the boiling point in temperature range between cooling surface and heating surface temperature. Table 1 shows the thermophysical properties of air and Diethylether. For example, the quantity of 1.0 mass $\%$ addition at $24^{\circ} \mathrm{C}$ of Diethylether is $0.1114 \mathrm{ml}$ or $0.07953 \mathrm{~g}$.

\subsection{Experimental Procedures}

The following experimental procedures are conducted.

1) Exhaust the working fluid which remains to test section by vacuum pump.

2) Air as a working fluid of the temperature of $24^{\circ} \mathrm{C}$ and pressure $101.3 \mathrm{kPa}$ (absolute humidity at this time is $0.0112 \pm 0.0007 \mathrm{~kg} / \mathrm{kg}^{*}$ ) is introduced into test section. Diethylether of specified quantity is thrown into test section by using digital buret.

3) A cooling surface and a heating surface are set to the experimental condition temperature.

4) A displacer piston is moved to upper side from the bottom side by actuator which is dominated by computer. At this time, the pressure, heating surface temperature, and working-fluid temperature of test section are measured, and it collects in a data logger.

\subsection{Experimental Conditions}

Temperature difference of heat source is set as 20 - $70 \mathrm{~K}$ containing the boiling point of phase change material. The high temperature heat source is set $80^{\circ} \mathrm{C}$ (or less) that aims as source temperature of hot-spring. The low temperature heat source is maintained $35^{\circ} \mathrm{C}$ (and below). The speed of a displacer piston is set as low-speed rotation $1-40 \mathrm{rpm}\left(u_{m c}=0.04-1.8 \mathrm{~m} / \mathrm{s}\right)$. The mixed rate to the working fluid (air) of PCM (Diethylether) is evaluated in not more than 4 mass\%.

Figure 2 indicates the time history of displacer piston position and velocity at this experimental condition. The position of a displacer piston is decided by the rotation angle regardless of number of revolutions. Sine wave operation is performed in the rise process of a displacer piston, because a displacer piston on the actual engine is controlled by rotation angle. The displacer piston operates by the computer controlled actuator. The heating process times are 0.75 seconds at $40 \mathrm{rpm}, 1.5$ seconds at $20 \mathrm{rpm}, 3.0$ seconds at $10 \mathrm{rpm}$ and 6.0 seconds at $5 \mathrm{rpm}$.

Figure 3 shows the variation of mean velocity on heating surface with crank angle. The flow velocities in the graph indicate that the values change in a process on each rotation. The heat transfer characteristic in a process evaluates by the flow velocity in each time.

Figure 4 indicates the variation of the cycle mean velocity on the heat transfer surface of the heating process. The heat transfer characteristic of the heating process in a cycle is examined using the cycle mean velocity on each number of rotations. The cycle mean velocity is calculated by next equation using process time.

$$
H=S t \times \sin \theta
$$


Table 1. Physical properties of air \& Diethylether [7].

\begin{tabular}{|c|c|c|c|}
\hline \multicolumn{2}{|c|}{ Working fluid } & Air & Diethylether $\mathrm{C}_{4} \mathrm{H}_{10} \mathrm{O}$ \\
\hline \multicolumn{2}{|c|}{ Boiling point ${ }^{\circ} \mathrm{C}$} & -193 & 34.6 \\
\hline \multirow{2}{*}{$\begin{array}{c}\text { Density } \\
\mathrm{kg} / \mathrm{m}^{3}\end{array}$} & L: Liquid & - & 713.8 \\
\hline & $V$ : Vapor & 1.181 & 3.308 \\
\hline \multicolumn{2}{|c|}{ Heat of evaporation J/g } & - & 392.1 \\
\hline \multicolumn{2}{|c|}{$C v \cdot \mathrm{J} /(\mathrm{g} \cdot \mathrm{K})$} & 0.7171 & 2.33:L \\
\hline \multicolumn{2}{|c|}{$\lambda \cdot \mathrm{W} /(\mathrm{m} \cdot \mathrm{K})$} & 0.00257 & $0.129: L$ \\
\hline
\end{tabular}

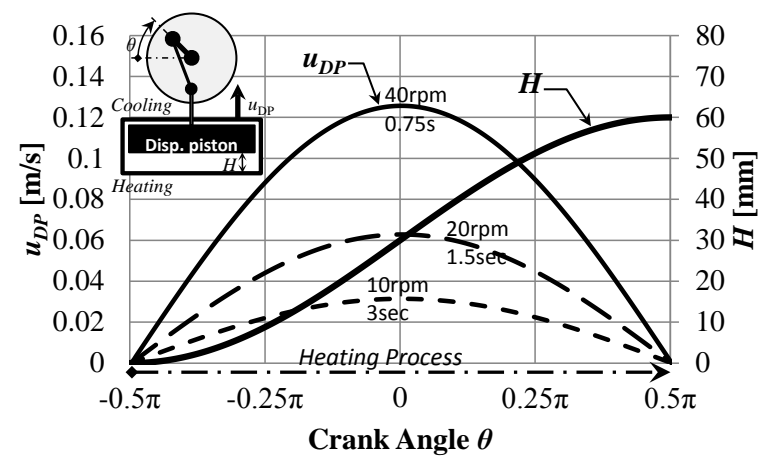

Figure 2. Position and velocity of displacer piston on process.

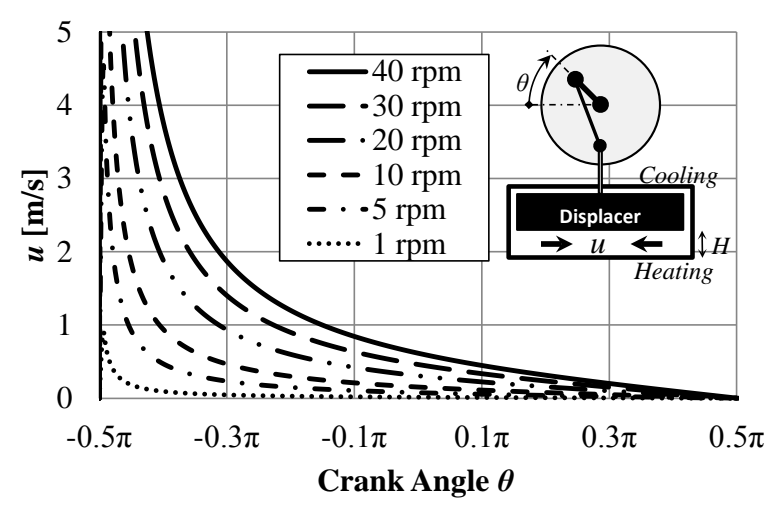

Figure 3. Variation of mean velocity with rotation angle.

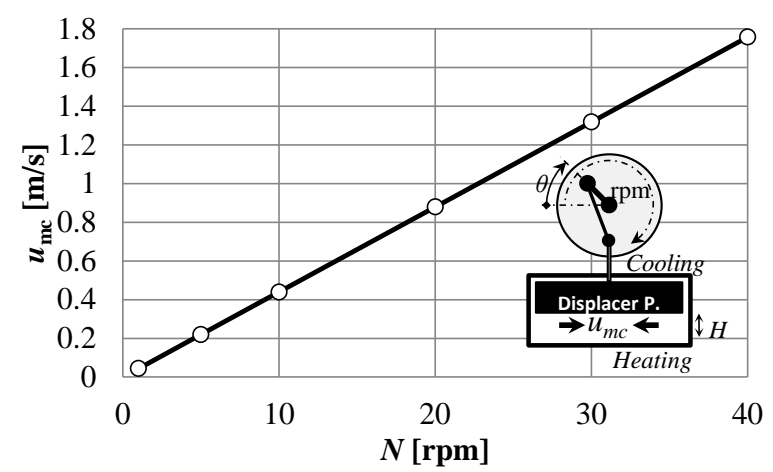

Figure 4. Variation of mean velocity on heating process. 


$$
\begin{gathered}
u=\frac{N}{60} \frac{\Delta H \times W_{D P} \times D_{D P}}{2 \times H \times D_{D P}} \\
\left.u_{m c}=\frac{1}{t_{p r}} \int_{-0.5 \pi}^{0.5 \pi} u \mathrm{~d} \theta \quad \text { (Integration range } t_{p r} \geq 0.1 \mathrm{sec}\right)
\end{gathered}
$$

The flow velocity on a heat transfer (heating) side is estimated by the following equations as Reynolds number. Two kinds of Reynolds-number are defined as $R e$ (using a flow velocity in a heating process) and $R e_{m c}$ (using an averaged flow velocity of the heating process on each number of rotations), respectively. The characteristic length is set to $1 / 2(L=150 \mathrm{~mm})$ of heating surface width, because the working fluid flows into center from both ends. The amount of additional phase change material is very little, so that the air value of dynamic viscosity is used for calculation.

$$
\begin{array}{r}
R e=\frac{u L}{v_{\mathrm{air}}} \\
R e_{m c}=\frac{u_{m c} L}{v_{\mathrm{air}}}
\end{array}
$$

The quantity of heat which a working fluid receives in heating process is calculated by the following equation with the application of a constant-volume change.

$$
q=G_{w} C_{w}\left(\frac{P}{P_{0}} T_{i}-T_{i-1}\right)
$$

In which, $C_{w}$ and $G_{w}$ are the specific heat at constant volume and the mass of working fluid. These values are calculated by using the thermophysical properties of composition.

$$
\begin{gathered}
C_{w}=C v_{\text {air }} G_{\text {air }}+C v_{d} G_{d} \\
G_{w}=(1-A d d) \times G_{\text {air }}+A d d \times G_{d}
\end{gathered}
$$

The quantity of heat in the heating process which a working fluid receives is calculated by next integral equation.

$$
\begin{gathered}
Q=\int_{-0.5 \pi}^{0.5 \pi} q \mathrm{~d} \theta \\
q_{m c}=\frac{Q}{t_{p r}}
\end{gathered}
$$

A heat transfer coefficient and Nusselt number are defined as follows.

$$
\begin{gathered}
\alpha=\frac{q}{S\left(T_{h}-T_{w 0}\right)} \\
N u=\frac{\alpha L}{\lambda_{\text {air }}}
\end{gathered}
$$

The averaged heat transfer coefficient and averaged Nusselt number in the heating process are defined by next equations.

$$
\begin{gathered}
\alpha_{m c}=\frac{1}{t_{p r}} \int_{-0.5 \pi}^{0.5 \pi} \alpha \mathrm{d} \theta \\
N u_{m c}=\frac{\alpha_{m c} L}{\lambda_{\text {air }}}
\end{gathered}
$$

The data of this study will be compared with the calculated values of next equation that is given Nusselt 
number of average laminar flow convective-heat-transfer on the plate [8] [9]. Pr is Plandtle number of air.

$$
N u_{t h}=0.664 \operatorname{Re}^{\frac{1}{2}} \operatorname{Pr}^{\frac{1}{3}}
$$

\section{Experimental Results and Discussions}

\subsection{Heat Exchange in Process}

Figure 5 shows the time history of the pressure increasing at $60 \mathrm{~K}$ in temperature difference of heat source, at 5 rpm in displacer piston speed. The pressure of test section is rising gently in response to the movement speed of displacer-piston. Then, pressure indicates the rapid increase that is caused by the high moving speed of a displacer-piston which shows the maximum velocity at the middle (3 seconds) of the process. At the last of process, it reaches to the maximum pressure by the small pressure increasing rate. The maximum pressures at the condition of using mixed-gas as working-fluid are larger than the condition of using air. The PCM (Diethylether) in a working fluid is changed from a liquid phase to gas phase by heating. It is certain that the maximum pressure enhancement is brought by the volume increasing by phase change.

Figure 6 shows the variation of exchange heat $q$ and exchange heat amount of heating process $Q$ with time at $55 \mathrm{~K}$ in temperature difference of heat source, at $10 \mathrm{rpm}$ in displacer piston speed. The exchange heat $q$ shows the maximum value at around the middle (1.5 seconds) of heating process. It is caused by the large movement speed of displacer-piston (the large flow rate of the working fluid to the heating side). The maximum of exchange heat $q$ is shown in little previous side from middle of a process (1.3 seconds). It is because the flow velocity on a heating surface is large in the first half of a process as above-mentioned. The exchange heat amount $Q$ is the integrated value of exchange heat $q$. The exchange heat is increased by integration of exchange heat, and the maximum exchange heat amount at finishing time of a process (3 seconds) is the value which is obtained heat amount of working fluid in heating process.

Figure 7 indicates the variation of heat transfer coefficient with time at the condition of $55 \mathrm{~K}$ and $5 \mathrm{rpm}$. The heat transfer coefficient indicates the peak at around the middle (3.0 seconds) of heating process. It is caused by the large flow rate of the working fluid to the heating side (the large movement speed of displacer-piston). The maximum of heat transfer coefficient is indicated in little previous side from middle of a process (2.7 seconds). It is because the flow velocity on a heating surface is large in the first half of a process as above-mentioned.

Figure 8 shows the relationship between averaged Nusselt number with averaged Reynolds number of heating process. The theoretical figure of the laminar flow $\mathrm{Nu}$ is shown in the same figure. The averaged $\mathrm{Nu}$ increases with increase of averaged Reynolds number. The flow space height keeps increase at the process, so that the flow on the heating surface of this study includes the forced convection flow. It is caused that the averaged $\mathrm{Nu}$ is larger than the theoretical figure of the laminar flow $\mathrm{Nu}$.

\subsection{Effect of Temperature Difference of Heat Source}

Figure 9 indicates the variation of the maximum exchange heat amount $Q_{e}$ with the temperature difference of heat source at the condition of 1 mass\% Diethylether. A large difference in temperature brings about increase of the amount of evaporation. The maximum exchange heat amount $Q_{e}$ increases with increasing of the temperature difference of heat source.

\subsection{Effect of Revolution Speed of Displacer Piston}

Figure 10 shows the variation of exchange heat amount ratio with number of revolution $N$ (process time). The exchange heat amount ratio decreases with increase of revolution number (or with decrease of process time). One or more values are measured in less than $20 \mathrm{rpm}$ because of its long process time. In the range of this study, the effect of phase-change-material addition is observed at less than (or more than 1.5 seconds process time) 20 rpm of revolution number. Effect of additional ratio of PCM.

Figure 11 indicates the variation of exchange heat amount ratio with the mass-additional-ratio. It is implied that the value of larger exchange heat amount ratio at the range with exceeding 1 is larger influence of PCM (Diethylether) addition. The exchange heat amount ratio shows the over one value at the range of less than 4 mass $\%$ on $55-60 \mathrm{~K}$ and 5 - $10 \mathrm{rpm}$. 


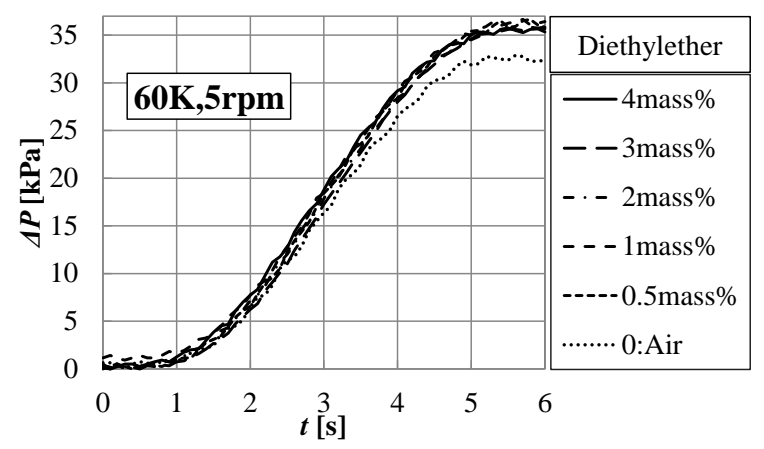

Figure 5. Time history of pressure increase at $60 \mathrm{~K}, 5$ rpm.

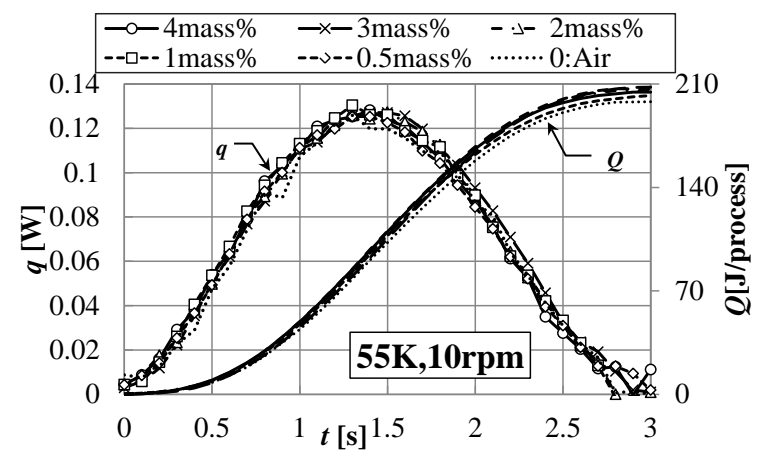

Figure 6. Variation of exchange heat and heat amount.

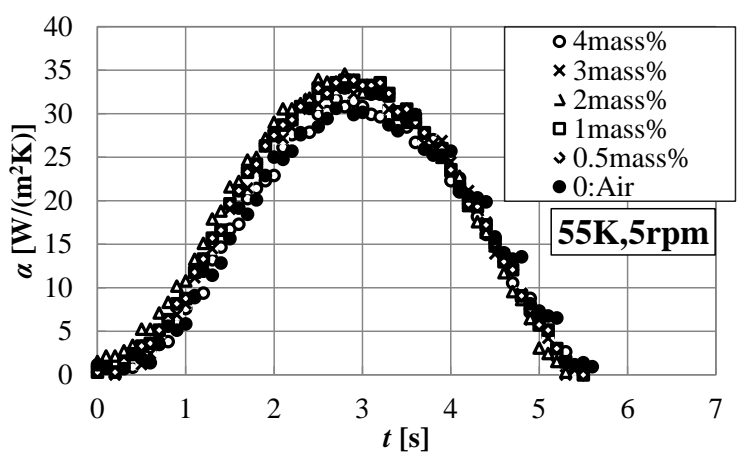

Figure 7. Time history of heat transfer coefficient.

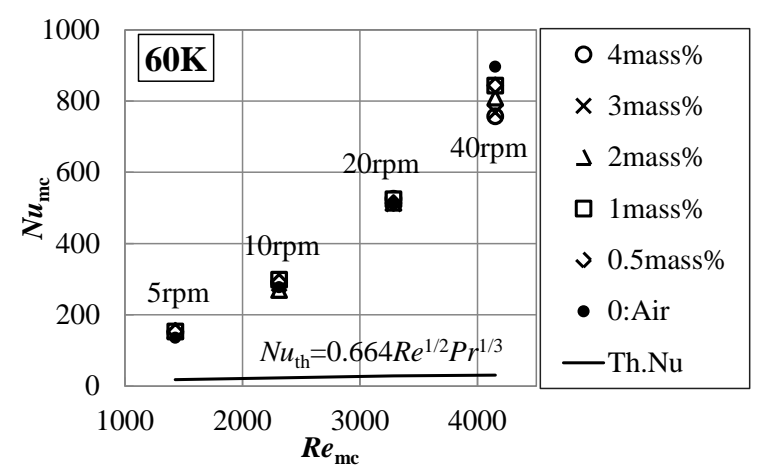

Figure 8. Variation of mean $\mathrm{Nu}$ with mean $\mathrm{Re}$ of process. 


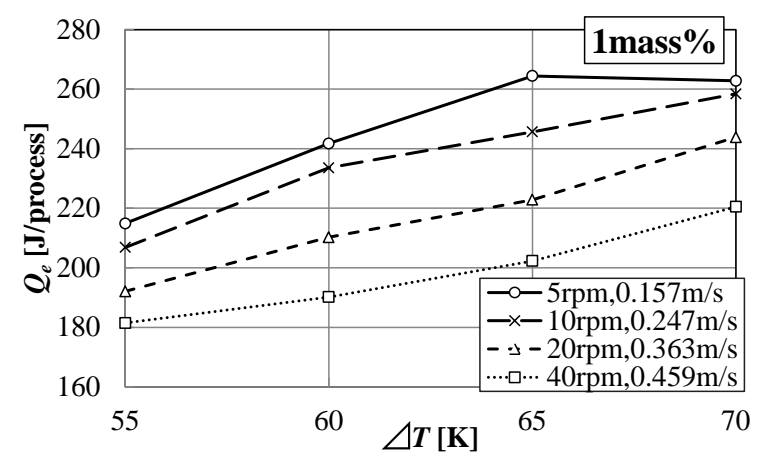

Figure 9. Relationship between heat $Q_{e}$ and $\Delta T$.

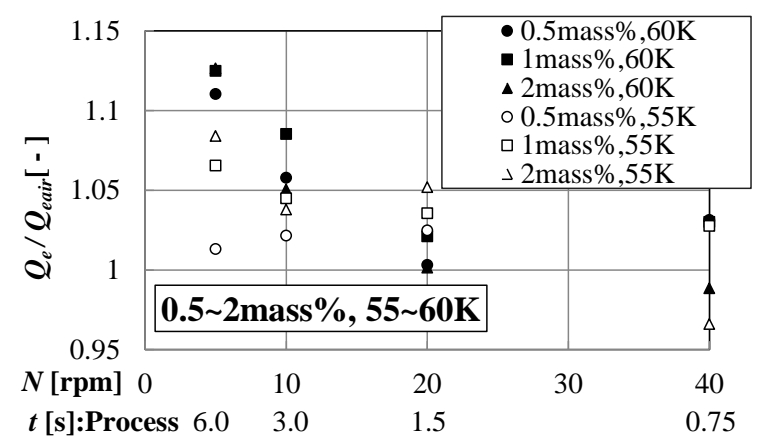

Figure 10. Exchange heat amount ratio with $N$ or $t$.

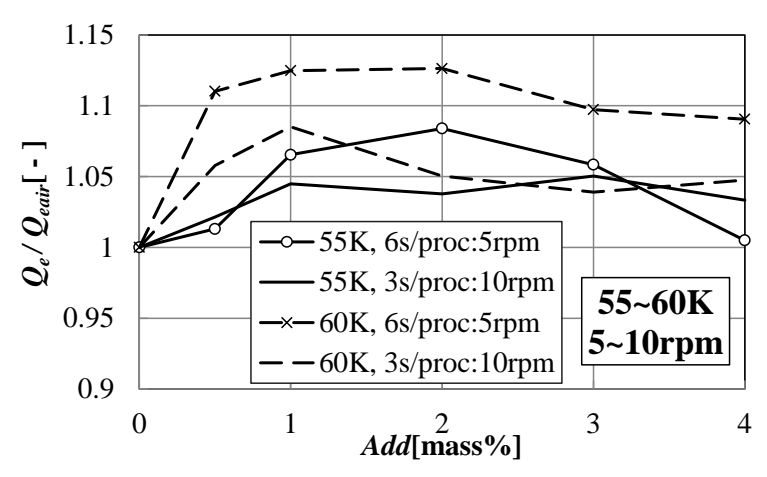

Figure 11. Variation of exchange heat amount ratio with Add.

\section{Conclusions}

Experimental study of the heat transfer by using the working fluid including PCM (Diethylether) is carried out, and the following conclusions are obtained.

1) It is suggested that the maximum of heat transfer coefficient is indicated in little previous side from middle of a process.

2) It is indicated that the exchange heat amount increases with increase of temperature difference of heat source.

3) It is clarified that the optimum ranges are $20 \mathrm{rpm}$ (the number of rotations) and less than 1 mass\% (the mass-additional-ratio of PCM).

\section{References}

[1] Ministry of the Environment, Government of Japan (2012) Hot Spring Use Situation Data 2012. 
[2] Osato, K., Muraoka, H. (2008) Hot Spring Binary Cycle Power Generation, the Latest Research and Development of Geothermal Energy. Journal of Japan Institute of Energy, 87, 812-818.

[3] Ogawa, Y., Watamabe, H., Sakai, M. and Tunou, K. (1994) Analysis of Thermoelectric Power Generation Using Thermoelectric Element. The Transactions of the Institute of Electronics, Information and Communication Engineers, J77-C-2(1), 34-43.

[4] Shiraki, T., Toda, F., Yamashita, Y., Ohkubo, T. and Kuribara, T. (2010) Development of Exhaust-Heat-Recovering Multiple Cylinder Type Stirling Engine. Proceeding of 13th Stirling Cycle Symposium, 1, 57-58.

[5] Tahara, T. and Akazawa, T. (2010) Development of 5 kW Class Waste Heat Recovery Stirling Engine: 1st Report, Design and Trial Running of Prototype Engine. Proceeding of 13th Stirling Cycle Symposium, 1, 19-20.

[6] Haramura, Y. and Nakamura, K. (2010) Heat Transfer Due to Annular Jet Induced by Displacer Motion (the Effects of Annular Channel Position and Cross Sectional Area). Proceeding of 12th Stirling Cycle Symposium, 1, 81-84.

[7] Japan Society of Thermophysical Properties (2008) Thermophysical Properties Handbook. Yokendo Co. Ltd., Tokyo, 469.

[8] The Japan Society of Mechanical Engineering (2008) JSME Heat Transfer Handbook, Maruzen Co. Ltd., Tokyo, 35.

[9] The Japan Society of Mechanical Engineering (2008) JSME Data Book of Heat Transfer. 5th Edition, Maruzen Co. Ltd., Tokyo, 40.

\section{Nomenclature}

\begin{tabular}{clcl}
\hline Add & Mass additional ratio to Air (mass\%) & Greek letters & \\
$C$ & Specific heat $(\mathrm{J} /(\mathrm{kg} \cdot \mathrm{K}))$ & $\alpha$ & Heat transfer coefficient $\left(\mathrm{W} /\left(\mathrm{m}^{2} \cdot \mathrm{K}\right)\right)$ \\
$D$ & Depth $(\mathrm{m})$ & $v$ & Kinematic viscosity $\left(\mathrm{m}^{2} / \mathrm{s}\right)$ \\
$G$ & Mass $(\mathrm{kg})$ & $\theta$ & Rotation angle $(\mathrm{rad})$ \\
$H$ & Height between displacer piston and heat transfer surface $(\mathrm{m}, \mathrm{mm})$ & $\lambda$ & Thermal conductivity $(\mathrm{W} /(\mathrm{m} \cdot \mathrm{K}))$ \\
$L$ & Length $(\mathrm{m})$ & Subscripts & \\
$N$ & Number of revolutions $(\mathrm{rpm})$ & 0 & Initial \\
$N u$ & Nusselt number $(-)$ & $a i r$ & Air \\
$P$ & Pressure (kPa) & $c$ & Cycle process \\
$\Delta P$ & Pressure difference $(\mathrm{kPa})$ & $d$ & Diethylether \\
$P r$ & Plandtle number $(-)$ & $D P$ & Displacer pinton \\
$q$ & Exchange heat per time $(\mathrm{J} / \mathrm{s})$ & $e$ & End of process \\
$Q$ & Exchange heat on heating process $(\mathrm{J} / \mathrm{process})$ & $h$ & Heat transfer surface \\
$S\left(=W_{h} \times D\right)$ & Area of heat transfer surface $\left(\mathrm{m}^{2}\right)$ & $i$ & Data step \\
$S t$ & Stroke $(60$ mm) & $m$ & Mean \\
$t$ & Time (s) & max & Maximum \\
$T$ & Temperature $\left({ }^{\circ} \mathrm{C}\right)$ & $p r$ & Process \\
$\Delta T$ & Temperature difference of heat source $(\mathrm{K})$ & $t h$ & The oritical \\
$u$ & Mean velocity on heat transfer surface $(\mathrm{m} / \mathrm{s})$ & $v$ & Constant volume \\
$W$ & Width (m) & $w$ & Working fluid $($ Air, Air + PCM) \\
\hline
\end{tabular}


Scientific Research Publishing (SCIRP) is one of the largest Open Access journal publishers. It is currently publishing more than 200 open access, online, peer-reviewed journals covering a wide range of academic disciplines. SCIRP serves the worldwide academic communities and contributes to the progress and application of science with its publication.

Other selected journals from SCIRP are listed as below. Submit your manuscript to us via either submit@scirp.org or Online Submission Portal.
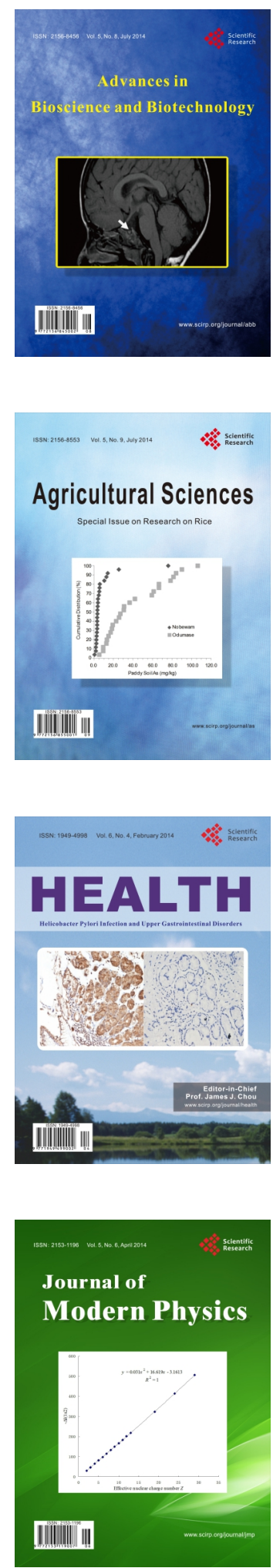
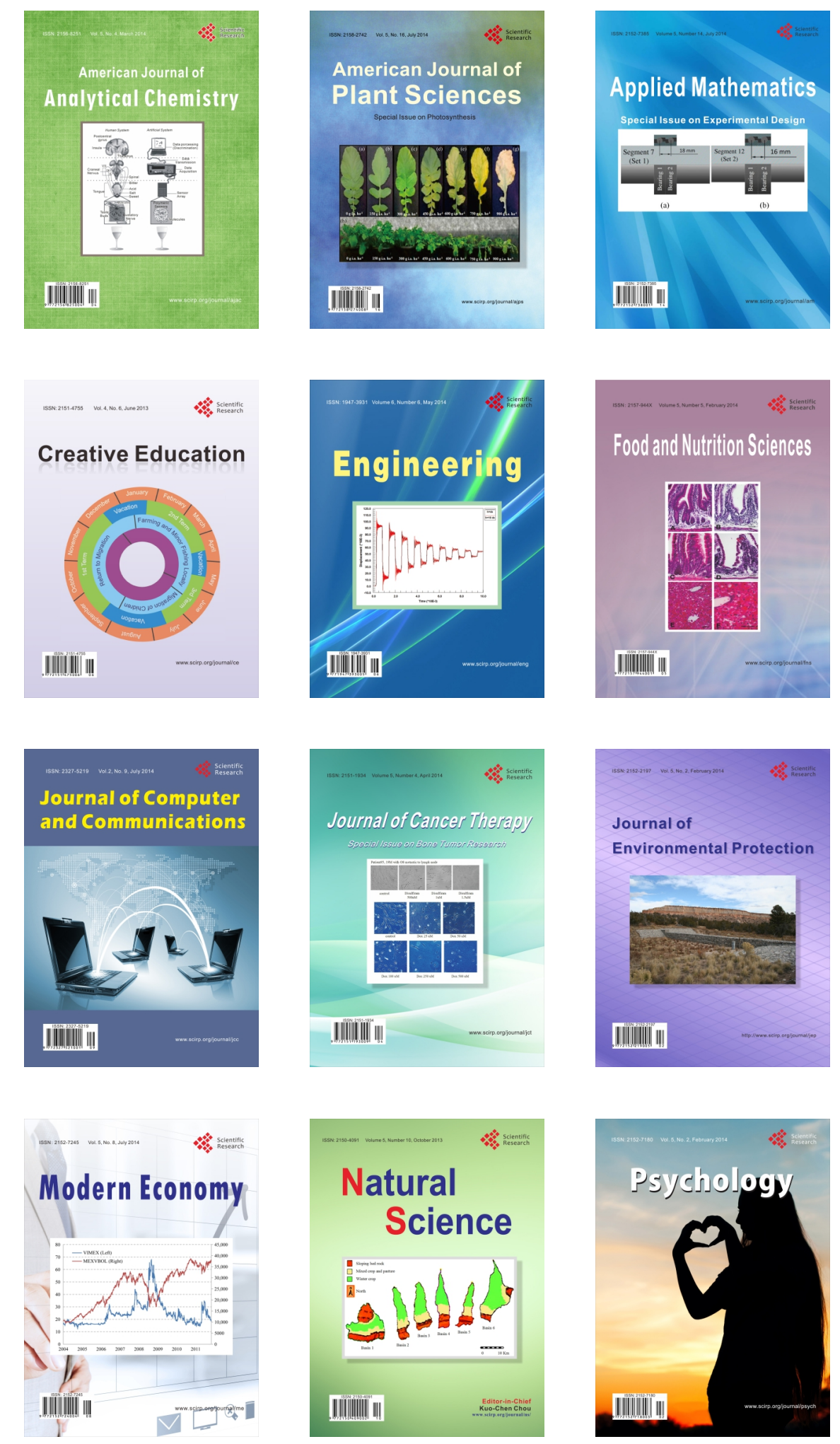